\title{
USING ORGANIC AMENDMENTS TO STABILIZE SAND-BASED ATHLETIC FIELDS DURING THE TURFGRASS ESTABLISHMENT PERIOD
}

\author{
A Thesis \\ Submitted to the Graduate Faculty \\ of the \\ North Dakota State University \\ of Agriculture and Applied Science
}

By

Thomas David Drietz
In Partial Fulfillment of the Requirements
for the Degree of
MASTER OF SCIENCE

\begin{abstract}
Major Department:
\end{abstract}
Plant Sciences

April 2019

Fargo, North Dakota 


\section{North Dakota State University Graduate School}

\section{Title}

Using Organic Amendments to Stabilize Sand-based Athletic Fields During the Turfgrass Establishment Period

\section{By}

Thomas David Drietz

The Supervisory Committee certifies that this disquisition complies with North

Dakota State University's regulations and meets the accepted standards for the degree of

\section{MASTER OF SCIENCE}

SUPERVISORY COMMITTEE:

Dr. Deying Li

Chair

Dr. Alan Zuk

Dr. Qi Zhang

Dr. Aaron Daigh

Approved:

April 12, 2019

Dr. Richard Horsley

Date

Department Chair 


\begin{abstract}
Athletic field rootzones are often sand-based for improved drainage. Sand-based rootzones may have stability issues if turfgrass is not fully established. Our objective was to use organic amendments to improve the stability of sand-based fields during the turfgrass establishment period and avoid overuse of inorganic materials, which have negative effects. We tested coconut coir, peat and wheat straw at $1 \%$ organic material, peat at $2 \%$ organic material, and an inorganic stabilizing fiber, StaLok, in the top $10 \mathrm{~cm}$ of the rootzone. Surface hardness, volumetric water content, traction, penetration resistance and visual quality were measured 2 to 4 months after construction of the plots. Surface hardness was greatest in the inorganic stabilizer and the wheat straw treatments. The kinetic penetration had no differences between the wheat straw (33.78-51.10 kPa) and the StaLok fibers (34.99-56.23 kPa). Wheat straw could be used to stabilize sand-based fields as an organic alternative to inorganic fibers.
\end{abstract}




\section{ACKNOWLEDGEMENTS}

I need to first thank my wife, Stephanie, for the support she has given me through my years of graduate school. I have been able to follow this path because of her. I am constantly amazed at her strength, will and character. She does more for me than I could ever know, and I hope to one day thank her properly. I also want to thank my sons, Dominic and Simon. It always makes me feel so good when I see them excited for me. I hope to be an example of a life-long learner to them, and that work is important but nothing is more important than family.

Thank you to my advisor, Dr. Deying Li, for contacting me about taking classes toward a master's degree. I would never have done this without him and his willingness to help me throughout the process.

Thank you to my committee members, Dr. Qi Zhang, Dr. Alan Zuk and Dr. Aaron Daigh. I appreciate the words of encouragement, corrections and revisions more than anyone would realize. 


\section{TABLE OF CONTENTS}

ABSTRACT




\section{LIST OF TABLES}

$\underline{\text { Table }}$

$\underline{\text { Page }}$

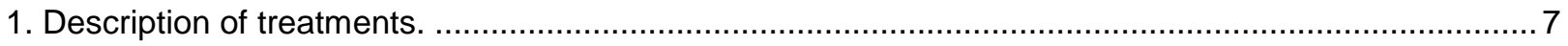

2. Particle analysis of the testing material used in the study..............................................................

3. Kentucky bluegrass turf stability in sand-based rootzones two months after construction in 2016 ......10

4. Kentucky bluegrass turf stability in sand-based rootzones three months after construction in 2016...10

5. Kentucky bluegrass turf stability in sand-based rootzones four months after construction in 2016 .... 11

6. Kentucky bluegrass turf stability in sand-based rootzones two months after construction in $2017 \ldots . . .11$

7. Kentucky bluegrass turf stability in sand-based rootzones three months after construction in $2017 \ldots 11$

8. Kentucky bluegrass turf stability in sand-based rootzones four months after construction in 2017 .... 12

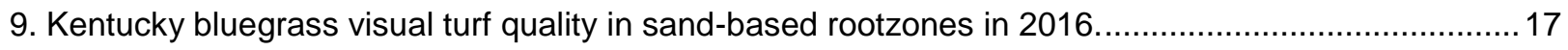

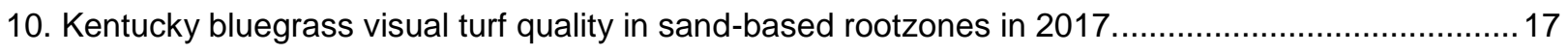

11. Correlation between parameters three months after the construction of plots in 2016. .................. 19

12. Correlation between parameter three months after the construction of plots in $2017 \ldots \ldots \ldots \ldots \ldots \ldots \ldots . . . .19$ 


\section{INTRODUCTION}

Many stadium complexes provide sports turf areas and the infrastructure to host particular sports, such as soccer, American football, baseball, etc. Sports turf surfaces may be bare grounds, synthetic turf or natural turfgrasses. Natural grass is the most preferred, especially for prestigious games and important venues (Beard and Green, 1994). Some games are sanctioned to be played only on natural grasses (Holmes and Cruz, 1994). Often, it is cost prohibitive to grow grass in an all-weather stadium with limited natural lighting. However, according to a survey by the National Football League Players Association, natural turfgrass is preferred by the majority of NFL players (NFL Players Association, 2010). A natural grass surface is softer and safer because living turfgrass is able to absorb impacts and give in response to certain levels of shear forces (Rogers, 1988). Natural turfgrass also has the ability to sanitize bodily fluids and unhealthy microorganisms (Turfgrass Resource Center). Natural turfgrass provides a cooler playing surface during the summer months so that heat stroke or other heat-related illnesses may be prevented during practices or games when air temperatures are high (Serensits et al., 2011). The amount of water required to maintain a cool synthetic surface was found to be more than that to maintain a warmseason turfgrass in New Mexico (Kanaan et al., 2018). A recent study found a 16\% increase in lower leg injuries per play on synthetic turf fields compared to natural turfgrass fields (Mack et al., 2018). The same study also found a higher rate of injury on synthetic turf when restricted to noncontact/surface contact injuries (Mack et al., 2018). Natural turfgrass athletic fields can be managed to a team's preference depending on situation or circumstance, thus, a "home-field advantage." Natural grass also is more appealing to viewers with the possibility to be mowed into different aesthetic patterns (Puhalla et al., 2010).

Player safety and performance are the primary considerations in sports turf management. Success is dependent on three fundamental characteristics of the surface: traction, hardness, and evenness or uniformity of the surface (Cockerham et al, 1993). These three components may have different weight for a given sport because each sport requires a unique surface performance. For example, a soccer player expects the ball to bounce off the surface consistently throughout the field, and if it does not the game itself may be affected. An American football player would expect to change directions quickly and without sliding, which could be the difference between being tackled and running 
for a touchdown. The combination of traction, hardness and evenness also determines other aspects of sports turf functionality, such as quality, safety, playability and aesthetics.

Safety is of utmost importance for all sports fields. An athlete should expect to be able to compete without worrying about an injury due to poor field conditions. This type of injury would be considered a non-contact or surface contact injury. A surface can be unsafe if it is unstable, too hard or too slippery. Stability of the rootzone and stability of the turfgrass surface are connected. Without the presence of one, there would be no stability in the other. An athlete expects to accelerate, decelerate and change direction on the field without slipping or sliding. A firm yet resilient, stable surface is needed for this to occur (Puhalla et al., 2010).

When field performance is emphasized, i.e. how well the field plays, the term 'playability' is often used. Playability can be further divided into interactions between players and surface, and between equipment and surface. Therefore, in some cases, the judgement depends on the coaches' or players' preferences. Nevertheless, playability can be tested or measured in terms of surface hardness, resilience, traction or friction of the surface, and ball bounce. The Fédération Internationale de Football Association (FIFA) has a set of standard testing procedures that help determine playability, such as ball rebound, angle ball rebound, shock absorption, vertical deformation and rotational resistance (Lulli et al, 2014; FIFA, 2015).

Aesthetics are important to the overall quality of an athletic field. Owners, managers, coaches and athletic directors want the fields to look the best for appealing to fans, television audiences, recruiting purposes and a number of other reasons. Fields are also scrutinized or complimented more by television audiences from across the country and the world, and because of the influence of social media.

The quality of sports turf is affected by turfgrass growth and vigor, well-knitted shoots and deep root systems. The rootzone media is vitally important to turfgrass health and playability of the athletic field. It has a direct impact on the performance and safety of the surface. High-quality natural turfgrass fields employ a sand-based rootzone for multiple reasons. Sand has a much larger particle size compared to silt and clay, therefore, sand creates higher ratios of large pores to allow excess water to drain through the soil profile, and to allow use of the field following, or even during, a rain event. Sand is commonly more resistant to compaction than finer soil materials when trafficked even in wet conditions 
(ASTM, 2004). Sand by itself does not hold sufficient water and nutrients needed for healthy growing turf. So, the United States Golf Association (USGA) recommends using a high-quality organic material mixed evenly with sand for the rootzone of putting greens (Hummel, 2000; USGA Green Section Staff, 2004). High performance sand-based rootzones for sports fields' construction have similar standards to that of the USGA and a guide is provided by the ASTM International (ASTM, 2004).

One of the issues with sand-based rootzones is the instability of the surface. Sports turf surface stability is not a well-defined physical property and can be directly or indirectly affected by surface hardness and traction of the rootzone. Although stability can be an issue with soil-based rootzones under certain circumstances, sand-based rootzones are generally more vulnerable. Sand is a non-cohesive material that relies on a film of water between particles to hold them together (Adams and Gibbs, 1994). Sand particle sizes can vary from 0.5 to $2.0 \mathrm{~mm}$ in diameter and can be rounded or angular, all of which contributes to the stability of the rootzone ( $\mathrm{Li}$ et al, 2009). Utilizing the proper sand when preparing the rootzone media is vitally important in providing surface stability.

Any factors that affect the growth of turfgrass can influence the surface stability. Natural turfgrass fields can, and will, be improved after construction with correct management practices. Natural turfgrass athletic fields need sufficient time to recover from the damages incurred during destructive events. Unfortunately, many fields are not given enough time to recover after events. The time required for recovery depends on a number of variables, especially climate, time of year, species of turfgrass and maturity of turfgrass. Often, in Northern climates, weather conditions are not conducive to turfgrass growth in the late fall, winter and very early spring months even with the availability of underground heating tubes, growth blankets and grow lights. Incidental damages, pests and abnormal weather can also lead to insufficient turfgrass growth even if adequate growing time is scheduled after rejuvenation, renovation or new construction.

Overuse of the athletic fields may cause accelerated deterioration of the turfgrass resulting in instability of the sports turf surface. Often, many non-sporting events, such as concerts, motocross and monster truck events, are held in professional and college stadiums and venues to increase revenue (Tencza et al., 2015). These extra events may be necessary to offset construction and maintenance costs. Natural turfgrass athletic fields in these stadiums can suffer significant damage due to these 
events. Despite the attempt to protect the field by utilizing mats or tarpaulin covers, the natural grass turf may still be damaged from compaction, lack of sunlight, restricted air flow through the canopy and the high temperatures under the protective coverings.

A common remedy to the turf damage in the situations previously mentioned is to re-sod the affected areas. Rejuvenation or renovation by seed is usually not an option after non-sporting events that damage the natural turf playing surface because the season may still be in progress. A juvenile grass would need 12 to 18 months on organic soils and 21 to 24 months on mineral soils to reach maturity for a safe playing surface (Rieke and Beard, 1969; Shearman et al., 2001; Li et al., 2011). Re-sodding the surface may take 3 to 6 months for a well-rooted turf field to be ready for games (Henderson et al., 2009). Washed sod (removing the existing soil from the sod by high-pressure water) is the quickest establishment method and a way to avoid soil layering problems. Re-establishment with washed sod also provides an opportunity to water deeper to encourage deep root growth and prevent infestation by weeds during the establishment period, as compared to other establishing methods including direct seeding, juvenile sod or unwashed sod (Canaway, 1993; Casimaty et al. 1993). Many other practices are used to increase stability in newly sodded turf, such as thick-cut sod, sod grown on plastic, use of turf covers, additional artificial lighting or a combination of these methods. Occasionally, immediate use of natural grass turf is needed without allowing time proper for sod establishment. In this case, game-ready turfgrass modules may be used instead (Williams, 2002; Anderson and VanLoo, 2005). These modules consist of a drainage layer, rootzone mix and generally use washed sod. They can be grown outside of a stadium and then moved into the stadium for certain events. The rootzone stability issues are to be taken seriously by sports turf managers during the first few months of sod establishment (Turgeon, 1999).

Many research studies have been conducted to determine the viability of a wide range of reinforcement materials in sand-based and soil-based rootzones to increase the stability of athletic field surfaces (Baker, 1997; Adams and Gibbs, 1989; Adams and Gibbs, 1994; Richards, 1994; Dest et al., 2005; Dickson et al., 2017).The focus of most of these inclusions are for high-wear areas where the turf cover may be reduced and rootzone stability is of great importance. Polypropylene fibers stabilize the surface and maintain traction levels in areas where the turf cover has been worn away by intense usage, but had little effect on areas where the turf cover was sufficient (Adams and Gibbs, 1989). Increases in 
traction were also noted in studies by Adams and Gibbs (1994) and Dest et al. (2005). However, not all published results recommend the use of the particular reinforcements studied based on only slight improvements of certain playing quality characteristics and the cost associated with using them. Since the inorganic fibers are not readily degradable, overuse or too much focus on the establishing phase can lead to the surface hardening over time (Dest et al., 2005). Other inorganic amendments (calcined clay, zeolite, fibers) can be added to the rootzone to reinforce stability when the turfgrass has been worn away or an insufficient root system exists in the new sod (Follis et al., 2013). Inorganic amendments have also been studied to determine their usefulness in alleviating soil compaction, to increase water retention and hydraulic conductivity and improve other soil physical properties (Li, 2001). The use of organic amendments (peat and compost) has been investigated for over 65 years for golf course green construction (Garman, 1952; Davis et al., 1970; Shepard, 1978). Peat in particular has been recommended to improve soil physical properties (USGA Green Section Staff, 1993; USGA Green Section Staff, 2004). Not all peat products are the equally effective. Therefore, it is important to use the appropriate peat when constructing a new rootzone. Peats can be contaminated with soil, excessive mineral content or fine humus particles that can affect water permeability and result in rootzone failure (Puhalla, 2010).

A standard testing procedure for turfgrass stability does not exist. Therefore, the measurements to detect surface hardness, penetration resistance and traction are used together to help determine the stability of a turfgrass athletic field surface. The Clegg hammer is a device that utilizes a 2.25-kg weight dropped from a predetermined height to measure the hardness of the turf surface (Clegg, 1976). This device gives a reading that can be used to determine uniform compaction across a large area. Penetration resistance is measured by a penetrometer. Push-type and hammer-driven penetrometers can be used for field characterization of soil strength (Hillel, 1998). With a push-type penetrometer, also known as a static penetrometer, the operator applies force that is normalized to the basal areas of the cone to form a parameter called the cone index (Herrick and Jones, 2002). The cone penetrometer uses a cone-shaped tip on a steel rod pushed through the turf and into the rootzone. The pressure required to force the rod into the rootzone is directly related to the amount of compaction (Gelernter and Stowell, 2001). Hammer-driven penetrometers, also known as dynamic penetrometers, supply a known amount of 
kinetic energy to the penetrometer which causes the penetrometer to move a distance through the soil (Herrick and Jones, 2002). Traction can be measured by a device consisting of cleats attached to a 150 $\mathrm{mm}$ diameter steel disc with $45 \mathrm{~kg}$ of weights added to the apparatus (Canaway and Bell, 1986). The device is then dropped onto the turf surface from an appropriate height to allow the cleats to sufficiently enter the turf. A torque wrench is used to determine the amount of torque needed to shear the turf.

The objective of this study was to identify an organic amendment that stabilizes the rootzone during the sod establishment period but degrades as the root system develops without competing for soil space, causing hydrophobicity, or causing the rootzone to be too hard when exposed to traffic. Our hypothesis is that the organic amendments (coconut coir, peat, wheat straw) incorporated with sand will create a stable rootzone mix. Therefore, creating a stable playing surface after establishing washed sod providing a solution for rootzone stability during the time when it is most vulnerable. This study will examine the physical characteristics of the surface and rootzone and relate them to stability. 


\section{MATERIALS AND METHODS}

The field study was conducted at the North Dakota Agricultural Experiment Station of North Dakota State University, Fargo, ND. The treatments consisted of sand-based rootzones mixed with three different organic amendments and one inorganic stabilizer (Table 1).

Table 1. Description of treatments.

\begin{tabular}{llll}
\hline Treatment & & OM (\%) & C:N \\
\hline Sand/Peat & 1\% organic material (gravimetric) & 0.85 & 40.4 \\
Sand/Peat & 2\% organic material (gravimetric) & 1.73 & 47.7 \\
Sand/Coconut coir & $1 \%$ organic material (gravimetric) & 0.73 & 92.9 \\
Sand/Wheat straw & $1 \%$ organic material (gravimetric) & 0.91 & 58.1 \\
Sand/StaLok & $0.4 \mathrm{~kg} \mathrm{~m}^{-2}$ & 0.07 & $\mathrm{n} / \mathrm{a}$ \\
\hline
\end{tabular}

Table 2. Particle analysis of the testing material used in the study.

\begin{tabular}{lcc|ccccccc}
\hline & \multicolumn{6}{c|}{ Soil Texture } & \multicolumn{7}{c}{ Sieve Aperture Size $(\mathrm{mm})$} \\
\hline & & & 2 & 1 & 0.5 & 0.25 & 0.15 & 0.05 \\
Component & 99.96 & 0.03 & 0.01 & 0.04 & 8.57 & 36.78 & 37.89 & 14.14 & 2.53 \\
Category & Sand & Silt & Clay & Gravel & $\begin{array}{c}\text { Very } \\
\text { coarse }\end{array}$ & Coarse & Medium & Fine & Very fine \\
\hline
\end{tabular}

The experiment design was a randomized complete block arrangement with three replications.

Plots used for the study measured $1.5 \mathrm{~m}$ by $3.7 \mathrm{~m}$. Existing turfgrass and $10 \mathrm{~cm}$ of rootzone was excavated in plot areas. Rootzone amendments were mixed in the top $10 \mathrm{~cm}$ depth of the rootzones by filling the excavated plots. The peat (Dakota Peat \& Equipment, Grand Forks, ND) and coconut coir (Millenniumsoils Coir, VGrove Inc., Ontario, Canada) were mixed using a cement mixer with the sand prior to placement in the excavated plot area to ensure proper mixing. The $1 \%$ organic material peat is commonly used in both USGA putting greens (USGA Green Section Staff, 2004) and ASTM International standards for athletic field construction (ASTM, 2004) The wheat straw was mixed in the plot while sand was added in 2-cm increments because of concerns that the wheat straw would not disperse well in large amounts if used at the same rate as peat. The rate of straw used in the study was based on similar amounts of organic material commonly used in sports turf rootzones (ASTM, 2004). However, different rates of straw were tested concurrently in a separate project to investigate the optimum rate, speed of degradation, and the effects of $\mathrm{C}: \mathrm{N}$ ratio in the rootzone on turfgrass. As in the case of wheat straw, the inorganic stabilizer, StaLok Fiber (Stabilizer Solutions, Inc., Phoenix, AZ), was mixed with sand in the plot in $2-\mathrm{cm}$ increments at a rate of $0.4 \mathrm{~kg} \mathrm{~m}^{-2}$ based on the manufacturer's recommendations. Plots were then 
compacted using a plate compactor in multiple directions to ensure coverage and complete compaction across each treatment plot. The finished rootzones were a $30 \mathrm{~cm}$ depth sand-based medium on $10-\mathrm{cm}$ pea rocks with 7.5- $\mathrm{cm}$ diameter corrugated drain tiles buried within the pea rocks at a $3 \mathrm{~m}$ spacing. Sand particle size analysis is shown in Table 2.

On 29 June 2016, one half of each plot was sodded using washed sod (Hanson Valley Sod, Hillsboro, ND). On 1 July 2016, the other half of each plot was seeded at $150 \mathrm{~kg} \mathrm{ha}^{-1}$ using a Kentucky bluegrass seed blend consisting of 'Park' and 'Dragon' in equal amounts (Rivard's Turf and Forage, East Grand Forks, MN). The focus of this study was on the sodded treatments. The seeded treatments were only used as a reference to develop a timeline for turfgrass establishment. Irrigation was applied to maintain moisture for proper establishment of both seeded and sodded treatment plots. After establishment, irrigation was applied to prevent drought stress. Plots were fertilized at a rate of approximately $25 \mathrm{~kg} \mathrm{~N}$ ha-1 $^{-1}$ at the beginning of grass establishment with an 18-24-5 granular starter fertilizer (The Andersons, Inc., Maumee, $\mathrm{OH}$ ) and after seedlings entered the third leaf stage. Additional fertilizer was added at a rate of approximately $50 \mathrm{~kg} \mathrm{~N} \mathrm{ha}^{-1}$ in mid-September. The turf was maintained at a five $\mathrm{cm}$ height and mowed on an as-needed schedule. The clippings were returned and no more than one-third of the leaf blade was removed at each mowing.

The experiment was repeated in 2017 on a plot adjacent to the 2016 study. The same procedures and timelines were followed except the sod was harvested from the NDAES from a 2-year old Kentucky bluegrass stand.

Measurements and data collection began two months after the turfgrass sod was installed; which was the earliest that the turfgrass root development was deemed sufficient for measurement by visual observation. The two months of turf establishment would allow subsequent measurements being conducted monthly in September to November. The measurements included volumetric water content, traction, surface hardness, soil shear strength and visual quality.

Volumetric water content of the rootzone was measured using a time domain reflectometry (TDR) probe (TRIME-FM, IMKO Micromodultechnik GmbH, Ettlingen, Germany). The unit has three probes with each measuring $15 \mathrm{~cm}$ in length. Three readings were taken for each treatment plot. 
Traction was tested using the weighted steel disc with cleats (Canaway and Bell, 1986). Measurements were recorded in Newton-meters. Three samples were taken from each plot.

Surface hardness was measured using a Clegg Soil Impact Tester (Model 95049A, Lafayette Instrument Company, Lafayette, IN) with a 2.25-kg hammer. Five drops from a height of $0.57 \mathrm{~m}$ were taken in each plot on the same location to record the average and maximum Clegg index, which was then transferred to unit of acceleration due to gravity, $\mathrm{m} \mathrm{s}^{-2}$.

Soil shear strength was measured using the United States Army Corps of Engineers cone penetrometer. One operator used this penetrometer every time measurements were taken. Three locations were tested in each plot on each evaluating date. A dynamic penetrometer, using the same cone as in the US Army Corps of Engineers penetrometer, was used with a 1-kg hammer dropped from 1 $\mathrm{m}$ height to drive the cone into the rootzones for three consecutive drops. The three penetration increments were recorded accurate to $0.5 \mathrm{~mm}$. One location was tested for kinetic penetration in each plot. The readings were then calculated into resistance $(\mathrm{kPa})$ using the equation reported by $\mathrm{Vaz}$ and Hopmans (2001).

Turf visual quality was evaluated using the 1 to 9 scale evaluation system used by the National Turfgrass Evaluation Program (NTEP), where 9 is the best, 6 is the minimum acceptable, and 1 is completely dead. Evaluations may vary depending on species, management levels and time of year.

The homogeneity of data collected over the two years was determined by the Levene test. The data of each month of each year were subjected to analysis of variance separately using the GLM procedure in SAS (SAS Institute, North Carolina, USA). Means were separated using Tukey's least significant difference when $F$-test was significant at the 0.05 probability level. Only the sodded portions of the plots were measured and subjected to data analysis. Simple correlations were determined in Excel (Microsoft, Washington, USA) and significance was determined by t-test with the equation: $t=$ $r_{1} \sqrt{n-2} / \sqrt{1-r_{2}^{2}}$ 


\section{RESULTS AND DISCUSSION}

The data collected over the two years were heterogeneous based on the Levene test. Therefore, data are presented separately by year. Results and discussion focus on the sodded area because only the sodded portions of the plots were fully established in the time frame available for data collection. The seeded areas are used as a reference only due to the slow establishment rates of the seeded portions of the plots. In general, the seeded areas were not as established as the sodded treatments two months after seeding.

Table 3. Kentucky bluegrass turf stability in sand-based rootzones two months after construction in 2016.

\begin{tabular}{|c|c|c|c|c|c|c|}
\hline \multirow[t]{3}{*}{ Treatments } & \multirow{2}{*}{$\begin{array}{c}\text { Moisture } \\
(\mathrm{v} / \mathrm{v})\end{array}$} & \multirow[t]{2}{*}{$\mathrm{G}_{\max }$} & \multirow[t]{2}{*}{ Traction } & \multicolumn{3}{|c|}{ Kinetic Penetration } \\
\hline & & & & $1^{\text {st }}$ Drop & $2^{\text {nd }}$ Drop & $3^{\text {rd }}$ Drop \\
\hline & $\%$ & $g$ & $\mathrm{Nm}$ & \multicolumn{3}{|c|}{$\mathrm{kPa}$} \\
\hline Sand/Peat (1\% OM) & 17.52ab & $5.6 \mathrm{~b}$ & 52.8 & $20.09 b$ & 22.23 & 20.09 \\
\hline Sand/Peat (2\% OM) & $18.47 a$ & $5.6 b$ & 53.2 & $19.56 \mathrm{~b}$ & 20.58 & 19.97 \\
\hline Sand/Coir (1\% OM) & 17.09ab & $5.6 \mathrm{~b}$ & 49.3 & $23.47 \mathrm{~b}$ & 21.63 & 20.59 \\
\hline Sand/Straw (1\% OM) & $16.40 \mathrm{ab}$ & $5.7 a b$ & 53.4 & $33.78 \mathrm{a}$ & 27.60 & 20.81 \\
\hline \multirow[t]{2}{*}{ Sand/StaLok } & $13.96 b$ & $6.3 a$ & 50.6 & $34.99 a$ & 28.01 & 21.28 \\
\hline & & & NS & & NS & NS \\
\hline
\end{tabular}

Different letters within a column indicate significant differences at the 0.05 level of probability using Tukey's LSD.

Table 4. Kentucky bluegrass turf stability in sand-based rootzones three months after construction in 2016.

\begin{tabular}{|c|c|c|c|c|c|c|}
\hline \multirow[t]{3}{*}{ Treatments } & \multirow{2}{*}{$\begin{array}{l}\text { Moisture } \\
(\mathrm{v} / \mathrm{v})\end{array}$} & \multirow[t]{2}{*}{$\mathrm{G}_{\max }$} & \multirow[t]{2}{*}{ Traction } & \multicolumn{3}{|c|}{ Kinetic Penetration } \\
\hline & & & & $1^{\text {st }}$ Drop & $2^{\text {nd }}$ Drop & $3^{\text {rd }}$ Drop \\
\hline & $\%$ & $g$ & $\mathrm{Nm}$ & \multicolumn{3}{|c|}{$\mathrm{kPa}$} \\
\hline Sand/Peat (1\% OM) & $9.61 a$ & $5.9 \mathrm{~b}$ & 58.2 & $23.00 \mathrm{~b}$ & $28.08 a b$ & 25.63 \\
\hline Sand/Peat (2\% OM) & $11.28 \mathrm{a}$ & $6.5 a b$ & 55.3 & $24.99 b$ & $26.23 b$ & 24.03 \\
\hline Sand/Coir (1\% OM) & $9.27 a b$ & $6.0 \mathrm{~b}$ & 61.5 & $25.11 b$ & 28.99ab & 22.84 \\
\hline Sand/Straw (1\% OM) & $7.37 \mathrm{bc}$ & $6.6 a b$ & 58.3 & $42.84 a$ & $35.86 a b$ & 24.88 \\
\hline Sand/StaLok & $6.94 \mathrm{c}$ & $7.1 \mathrm{a}$ & 62.3 & $38.27 a$ & $39.47 a$ & 30.78 \\
\hline & & & NS & & & NS \\
\hline
\end{tabular}

Different letters within a column indicate significant differences at the 0.05 level of probability using Tukey's LSD. 
Table 5. Kentucky bluegrass turf stability in sand-based rootzones four months after construction in 2016.

\begin{tabular}{|c|c|c|c|c|c|c|}
\hline \multirow[t]{3}{*}{ Treatments } & \multirow{2}{*}{$\begin{array}{c}\text { Moisture } \\
(\mathrm{v} / \mathrm{v})\end{array}$} & \multirow[t]{2}{*}{$G_{\max }$} & \multirow[t]{2}{*}{ Traction } & \multicolumn{3}{|c|}{ Kinetic Penetration } \\
\hline & & & & $1^{\text {st }}$ Drop & $2^{\text {nd }}$ Drop & $3^{\text {rd }}$ Drop \\
\hline & $\%$ & $g$ & $\mathrm{Nm}$ & \multicolumn{3}{|c|}{$\mathrm{kPa}$} \\
\hline Sand/Peat (1\% OM) & $7.81 \mathrm{ab}$ & $6.2 \mathrm{ab}$ & 66.1 & $24.69 b$ & $25.01 \mathrm{c}$ & $22.51 b$ \\
\hline Sand/Peat $(2 \%$ OM) & $8.93 a$ & $6.5 a b$ & 67.8 & $29.41 b$ & $26.55 b c$ & $21.81 b$ \\
\hline Sand/Coir ( $1 \%$ OM) & 7.53ab & $6.0 \mathrm{~b}$ & 64.6 & $26.16 \mathrm{~b}$ & $25.20 c$ & $24.40 \mathrm{ab}$ \\
\hline Sand/Straw (1\% OM) & $6.27 \mathrm{~b}$ & $6.9 a b$ & 60.9 & $38.90 \mathrm{a}$ & $51.86 a$ & $35.19 a$ \\
\hline Sand/StaLok & $5.79 b$ & $7.2 \mathrm{a}$ & 64.1 & $43.10 \mathrm{a}$ & $45.91 \mathrm{ab}$ & $35.86 a$ \\
\hline & & & NS & & & \\
\hline
\end{tabular}

Different letters within a column indicate significant differences at the 0.05 level of probability using Tukey's LSD.

Table 6. Kentucky bluegrass turf stability in sand-based rootzones two months after construction in 2017.

\begin{tabular}{|c|c|c|c|c|c|c|}
\hline \multirow[t]{3}{*}{ Treatments } & \multirow{2}{*}{$\begin{array}{c}\text { Moisture } \\
(\mathrm{v} / \mathrm{v})\end{array}$} & \multirow[t]{2}{*}{$\mathrm{G}_{\max }$} & \multirow[t]{2}{*}{ Traction } & \multicolumn{3}{|c|}{ Kinetic Penetration } \\
\hline & & & & $1^{\text {st }}$ Drop & $2^{\text {nd }}$ Drop & $3^{\text {rd }}$ Drop \\
\hline & $\%$ & $g$ & $\mathrm{Nm}$ & \multicolumn{3}{|c|}{$\mathrm{kPa}$} \\
\hline Sand/Peat (1\% OM) & $14.2 a b$ & $4.43 b$ & 46.56 & $35.95 b$ & $45.55 b$ & $58.05 b$ \\
\hline Sand/Peat ( $2 \%$ OM) & $15.87 a$ & $4.23 b$ & 46.78 & $44.88 a b$ & $49.65 b$ & $51.66 \mathrm{~b}$ \\
\hline Sand/Coir ( $1 \%$ OM) & $11.34 \mathrm{~b}$ & $3.93 \mathrm{~b}$ & 46.56 & $40.59 \mathrm{ab}$ & $65.08 \mathrm{ab}$ & $57.15 b$ \\
\hline Sand/Straw (1\% OM) & $11.63 b$ & $5.07 a$ & 46.44 & $47.46 a b$ & $71.97 a b$ & $80.13 a$ \\
\hline Sand/StaLok & $10.36 b$ & $5.27 a$ & 43.78 & $51.23 a$ & $73.38 a$ & $87.75 a$ \\
\hline & & & NS & & & \\
\hline
\end{tabular}

Different letters within a column indicate significant differences at the 0.05 level of probability using Tukey's LSD.

Table 7. Kentucky bluegrass turf stability in sand-based rootzones three months after construction in 2017.

\begin{tabular}{|c|c|c|c|c|c|c|}
\hline \multirow[t]{3}{*}{ Treatments } & \multirow{2}{*}{$\begin{array}{c}\text { Moisture } \\
(\mathrm{v} / \mathrm{v})\end{array}$} & \multirow[t]{2}{*}{$G_{\max }$} & \multirow[t]{2}{*}{ Traction } & \multicolumn{3}{|c|}{ Kinetic Penetration } \\
\hline & & & & $1^{\text {st }}$ Drop & $2^{\text {nd }}$ Drop & $3^{\text {rd }}$ Drop \\
\hline & $\%$ & $g$ & $\mathrm{Nm}$ & \multicolumn{3}{|c|}{$\mathrm{kPa}$} \\
\hline Sand/Peat (1\% OM) & 10.46ab & $4.37 \mathrm{~b}$ & 55.66 & $35.19 c$ & $50.06 \mathrm{~b}$ & 64.02ab \\
\hline Sand/Peat (2\% OM) & $12.28 \mathrm{a}$ & $4.33 b$ & 49.22 & 45.39abc & $52.41 \mathrm{~b}$ & $55.97 \mathrm{~b}$ \\
\hline Sand/Coir (1\% OM) & $7.88 \mathrm{~b}$ & $3.97 b$ & 53.22 & $40.35 b c$ & $67.39 a$ & 77.29ab \\
\hline Sand/Straw (1\% OM) & $7.87 \mathrm{~b}$ & $4.7 a b$ & 46.33 & $51.10 a b$ & $70.08 a$ & $85.17 a$ \\
\hline Sand/StaLok & $7.06 \mathrm{~b}$ & $5.43 a$ & 48.44 & $54.31 a$ & $75.41 a$ & $86.53 a$ \\
\hline & & & NS & & & \\
\hline
\end{tabular}

Different letters within a column indicate significant differences at the 0.05 level of probability using

Tukey's LSD. 
Table 8. Kentucky bluegrass turf stability in sand-based rootzones four months after construction in 2017.

\begin{tabular}{|c|c|c|c|c|c|c|}
\hline \multirow[t]{3}{*}{ Treatments } & \multirow{2}{*}{$\begin{array}{c}\text { Moisture } \\
(\mathrm{v} / \mathrm{v})\end{array}$} & \multirow[t]{2}{*}{$\mathrm{G}_{\max }$} & \multirow[t]{2}{*}{ Traction } & \multicolumn{3}{|c|}{ Kinetic Penetration } \\
\hline & & & & $1^{\text {st }}$ Drop & $2^{\text {nd }}$ Drop & $3^{\text {rd }}$ Drop \\
\hline & $\%$ & $g$ & $\mathrm{Nm}$ & \multicolumn{3}{|c|}{$\overline{\mathrm{kPa}}$} \\
\hline Sand/Peat (1\% OM) & 7.72ab & $5.73 a b$ & 49.89 & $37.98 b$ & $46.15 b$ & $63.27 \mathrm{~b}$ \\
\hline Sand/Peat (2\% OM) & $9.39 a$ & $6.57 a b$ & 50.78 & $37.20 \mathrm{~b}$ & $60.45 a$ & $66.57 a b$ \\
\hline Sand/Coir (1\% OM) & $7.31 \mathrm{ab}$ & $4.47 \mathrm{~b}$ & 49.55 & $44.61 \mathrm{ab}$ & $64.53 a$ & 67.49ab \\
\hline Sand/Straw (1\% OM) & $6.87 a b$ & 6.73ab & 52.78 & 46.59ab & $65.28 a$ & $82.51 \mathrm{a}$ \\
\hline Sand/StaLok & $6.023 b$ & $7.33 a$ & 48.89 & $56.23 a$ & $68.63 a$ & $81.19 a$ \\
\hline & & & NS & & & \\
\hline
\end{tabular}

Different letters within a column indicate significant differences at the 0.05 level of probability using Tukey's LSD.

\section{Moisture content}

Significant differences in rootzone moisture content were found between the treatments for all dates. This was especially apparent in the peat with $2 \%$ organic material treatment having the highest levels of volumetric water content throughout the study (Tables 3 to 8 ). The lowest measured volumetric water content occurred in the inorganic StaLok treatment during each month in both years, however, not all measurements were significantly different. The hydrophobic inorganic fibers do not have the ability to retain moisture in the soil profile and are used primarily for the purpose of rootzone stability. The plots had especially low moisture in the soil during the November measurements because of a lack of precipitation and the winterization of the irrigation system to avoid freezing damages to the underground components.

A higher moisture content in the rootzone helps to establish the grass quickly, especially for sandbased systems (Cook and Baker, 1998). Increasing soil moisture with organic amendments can compensate for the lower water holding capacity of washed sod (Anderson et al., 2014). Too much organic matter can decrease water infiltration rates and water conductivity (Baker et al., 1999), therefore, too much organic matter should be avoided despite its ability to stabilize the rootzone by holding higher amounts of water. Dickson et al. (2018) reported reduced turfgrass stability in rootzones with the highest soil water content tested $\left(0.30-0.37 \mathrm{~m}^{3} \mathrm{~m}^{-3}\right)$. Therefore, care should be taken to avoid over-applying water to the turfgrass prior to a sporting event. The highest soil moisture content achieved by adding organic amendment in this study was still within the optimal range (USGA Green Section Staff, 1993). 


\section{Surface hardness}

The inorganic stabilizer StaLok treatment yielded the highest hardness reading ( $G_{\max }$ rating) for all dates tested in both years (Tables 3 to 8 ). All surface hardness measurements were well under the recommended safe playing surface limits set by the NFL (Bradley, 2014). The organic treatments, while not always significantly different from the inorganic treatment, produced softer surfaces. It could be reasonably assumed that the factors contributing to greater verdure, such as higher organic matter content, would help cushion compacting forces, as stated by Carrow and Petrovic (1992).

Surface hardness is either measured by the energy absorbed by the surface as indicated by $G_{\max }$ (Puhalla et al., 2010) or by vertical deformation (Baker and Canaway, 1993). However, hardness is not a direct measurement of the surface stability, which includes deformation of the playing surface in three dimensions. There are no standards for any sport that specify a range of surface hardness that would be considered safe, but both the NFL and FIFA have standards for the highest hardness values to deem a field unsafe (Bradley, 2014; FIFA, 2015). A surface that is too soft is much less stable than one that is too hard but both may be considered unsafe. If the surface is too soft it may be slippery and create divots when athletes plant their feet or twist and turn on the field. If the surface is too hard, or the rootzone is too compacted, injuries may be more likely to occur (Walker and Walker, 2018).

\section{Traction}

There were no significant differences in traction in any month of either year studied. The statistical analysis shows a wide range in the $R^{2}$ values $(0.27-0.83)$. The large range of $R^{2}$ values suggests this measurement has greater error and is, therefore, less reliable to detect real differences in traction between the treatments. Stier et al. (1999) found traction values less than $10 \mathrm{Nm}$ result in sod that can be easily torn from the rootzone. Therefore, $10 \mathrm{Nm}$ can be considered a minimum value of traction for sports turf. Dickson et al. (2018) suggested hybrid Cynodon dactylon athletic fields should have minimum traction values of $18 \mathrm{Nm}$. All of the treatments tested in our study had values considerably higher than these lowest recommendations.

A numerical trend of increases were observed in all treatments for year one (Tables 3 to 5). The notable increases in each month could be contributed to the growth of the turfgrass and accumulation of 
thatch, as observed by Follis et al. (2013). Rogers (1988) also reported that the presence of roots increased traction regardless of species selection. Traction values in year two (Tables 6 to 8 ) had some increase in all treatments from the second month $(43.78-46.78 \mathrm{Nm})$ to third month $(46.33-55.66 \mathrm{Nm})$, with the exception of the wheat straw (46.44 to $46.33 \mathrm{Nm})$.

Because traction is measured on a horizontal plane with shallow cheats (Bell et al., 1985), the sod quality, as well as maturity, dictates the values. A rootzone with better water holding capacity may result in faster rooting and turfgrass establishment from sod (Shim et al., 2004). A well-knit turfgrass stand also contributes to a stronger surface (Beard et al., 1977). Nevertheless, the actual deformation during a sporting event may happen at an angle, and the traction measurement will not capture all the features of the stability.

Adams and Gibbs (1989) found the use of polypropylene fibers provided stability and traction in intensively worn areas but no differences in traction where turf cover was sufficient. In our study, turf cover was always sufficient and may be a factor in the minimal differences seen between treatments. McNitt and Landschoot (2005) reported traction initially increased with the increase in wear levels, probably due to the firming of the surface. However, the overall traction was not affected by the inclusion of reinforcing materials in the study (McNitt and Landschoot, 2005). In our findings, there were inconsistent correlations between surface hardness and traction. Our study did not include traffic simulations but would be recommended for any future research to determine the effectiveness of these treatments to provide traction and stability when turfgrass has been worn away.

\section{Kinetic penetration}

Penetration resistance is an empirical estimation of soil mechanical properties and is often inferred as an indirect measurement of soil compaction (Depdew et al., 1998). Cone penetration resistance was significantly different in many of the testing dates and between subsequent drops into the rootzone. The inorganic treatment of sand/StaLok had consistently higher penetration resistance than the organic amendment treatments except for wheat straw. Both peat treatments and the coconut coir treatment were consistently easier to penetrate in all drops on all testing dates (Tables 3 to 8). 
In the first year study (Tables 3 to 5), slight increases were noted in the first drop between the second and third months after construction in the coconut coir $(23.47$ to $25.11 \mathrm{kPa}), 1 \%$ organic material peat (20.09 to $23.00 \mathrm{kPa}$ ) and the StaLok fiber treatments (34.99 to $38.27 \mathrm{kPa})$. Larger increases were noted in the first drop between the second and third months in the straw ( 33.78 to $42.84 \mathrm{kPa}$ ) and the $2 \%$ organic material peat treatments (19.56 to $24.99 \mathrm{kPa})$. All treatments, except the straw showed increased penetration resistance in the fourth month compared to the third month.

The second drops in the first year measurements showed much larger increases in the StaLok fiber (28.01 to $39.47 \mathrm{kPa}$ ) and straw treatments $(27.60$ to $35.86 \mathrm{kPa}$ ) between the second and third month. A large increase in penetration resistance of $16.0 \mathrm{kPa}$ was noted in the inorganic treatment between the third and fourth month after construction. In the peat treatments and the coconut coir treatment, the second and third drops were very similar to the measurements taken during the months tested after construction. Increases in penetration resistance were found in the third drop for both wheat straw and StaLok treatments.

In the second year (Tables 6 to 8), similar results were found by our testing through most of the treatments compared to year one. The first drop in the $1 \%$ organic material peat, the $2 \%$ organic material peat and the coconut coir treatments were relatively equal through all months tested. The wheat straw treatment increased between months two and three (47.46 to $51.10 \mathrm{kPa})$ but decreased between months three and four ( 51.10 to $46.59 \mathrm{kPa}$ ). The inorganic treatment increased for the first drop between each month.

For the second drop, all treatments increased from month two to month three and then decreased from month three to month four with the exception of the $2 \%$ organic material peat treatment $(52.41$ to $60.45 \mathrm{kPa})$. The treatments showed increased penetration resistance once again during the third drop between the second and third months after construction while the StaLok treatment slightly decreased (87.75-86.53 kPa). Decreases were measured again in month four compared to month three with the exception of the $2 \%$ organic material peat treatment $(55.97-66.57 \mathrm{kPa})$.

Higher penetration resistance in the first drop shows the surface and top layer of the rootzone is not as prone to loose footing on an athletic field. A firm surface and top portion of the rootzone, as shown by the penetrometer measurements, will create a more stable athletic surface. Van Wijk (1980) noted that 
increasing organic matter also increased penetration resistance presumably by the increased growth in the turfgrass and root system. Extensively used areas of an athletic field may have lower penetration resistance compared to intensively used areas because of the foot traffic associated with the particular sport. Van Wijk (1980) provided measurements for each area of a soccer field and its recommended penetration resistance based on the intensity of the play it receives. Orchard (2001) recommended the use of only the first drop averages of the penetrometer because it was found to have a stronger relationship with injury than the three-drop average because the athletes' cleats or studs will not penetrate below the top $1-2 \mathrm{~cm}$ of the surface. Subsequent drops into the rootzone measures the soil displacement and the stability of the rootzone itself.

\section{Static penetration}

A primary concern in using the static cone penetrometer is the large variability associated with the method even at close locations (O'Sullivan et al., 1987). The variance also increases with insertion speed (Freitag, 1968) and depth (Bradford et al., 1971). Therefore, it is a common occurrence to notice the results are often not normally distributed (Gerrard, 1982).

The static penetration of the rootzone was measured in this study but the results are not included in the results and discussion because of the large variations and statistical insignificance. The $R^{2}$ values ranged from 0.25 to 0.53 in the first year and from 0.39 to 0.90 in the second year.

Visual quality

Only the subjective visual ratings at three and four months after construction in both years (Tables $9 \& 10$ ) was included here because the results prior to the third month were very similar in all treatments. Only slight differences in quality existed between treatments. The $2 \%$ organic material peat treatment was the highest rated during each month. The inorganic and wheat straw treatments were the lowest rated on several of the testing dates. The moisture content of the rootzones is the primary cause of the color and quality differences. The wheat straw treatment had a higher C:N ratio, 58.1 (Table 1), than the peat amended rootzones. However, the ratio was not considered fully responsible for the slightly poor visual quality because the coconut coir treatment had a much higher C:N ratio, 92.9 (Table 1), but 
produced equal or better turf quality than the wheat straw treatment. The results indicate that additional factors should be investigated with wheat straw amendments, especially when higher rates are justified.

Establishment of the sod was noticeably quicker by visual and physical inspection in the two peat treatments and slower in the inorganic treatment. The quantification of turfgrass establishment was not tested as part of the study but done by visual inspection of the sod. Establishment of the seeded portion of the plots showed a similar trend in that the seed in the peat treatments was notably quicker to germinate and spread than the inorganic and wheat straw treatments. However, none of the seeded plots were mature enough to warrant testing on any of the testing dates in either year. While sod selection and establishment are very important to the stability of a playing surface, wheat straw can provide additional stability to an athletic playing surface in a short timeframe when incorporated into a sand-based rootzone. Visual quality may not suffice for some professional venues but could be enhanced by additional fertility at rates to be determined in future research.

Table 9. Kentucky bluegrass visual turf quality in sand-based rootzones in 2016.

\begin{tabular}{lcc}
\hline Treatments & & \\
\hline & 3 months after construction & 4 months after construction \\
\cline { 2 - 3 } Sand/Peat $(1 \%$ OM) & $7.0 \mathrm{ab}$ & $5.7 \mathrm{ab}$ \\
Sand/Peat $(2 \%$ OM) & $8.0 \mathrm{a}$ & $6.7 \mathrm{a}$ \\
Sand/Coir $(1 \%$ OM) & $6.7 \mathrm{ab}$ & $6.0 \mathrm{ab}$ \\
Sand/Straw $(1 \%$ OM) & $6.3 \mathrm{~b}$ & $6.0 \mathrm{ab}$ \\
Sand/StaLok & $6.3 \mathrm{~b}$ & $5.0 \mathrm{~b}$
\end{tabular}

Different letters with a column indicate significant differences at the 0.05 level of probability using Tukey's LSD.

Table 10. Kentucky bluegrass visual turf quality in sand-based rootzones in 2017.

\begin{tabular}{lcc}
\hline Treatments & & \\
\hline & 3 months after construction & 4 months after construction \\
\cline { 2 - 3 } Sand/Peat (1\% OM) & 6.0 & $6.3 \mathrm{a}$ \\
Sand/Peat $(2 \%$ OM) & 6.0 & $6.5 \mathrm{a}$ \\
Sand/Coir (1\% OM) & 6.0 & $6.2 \mathrm{a}$ \\
Sand/Straw (1\% OM) & 6.0 & $5.8 \mathrm{ab}$ \\
Sand/StaLok & 5.8 & $4.8 \mathrm{~b}$ \\
\hline
\end{tabular}

Different letters with a column indicate significant differences at the 0.05 level of probability using Tukey's LSD. 


\section{Correlations}

The correlation between parameters was analyzed for the third month after construction in both years (Tables $11 \& 12$ ). The third month after construction represented the best maturity of the sod prior to the winterization of the irrigation system.

Rootzone water content and surface hardness $\left(G_{\max }\right)$ were negatively correlated in both years which was significant in 2017 but not in 2016 at the 95\% probability level of confidence. The inverse relationship of water content in the rootzone and surface hardness was also reported by Dickson et al. (2018). That study also proposed that surface hardness can be manipulated by adjusting the soil water content in athletic fields. The treatments with higher rootzone moisture content were generally softer than the drier rootzones. This is consistent with previous research that showed moisture content was a factor in surface hardness (Baker, 1989; Rogers and Waddington, 1992; Goodall et al., 2005). The drier rootzones (StaLok and wheat straw treatments) showed the highest surface hardness and cone penetration resistance measurements. This could potentially indicate that the stabilization by fibers and straw is less dependent on moisture and can have a high penetration resistance even in relatively dry conditions.

Traction showed no significant correlations with moisture or surface hardness in either year of the study. Many studies have shown large positive correlations between traction and ground cover (Holmes and Bell, 1986; Baker, 1991; McClements and Baker, 1994). This study had sufficient ground cover throughout the time frame but was not specifically measured except by subjective visual ratings.

Strong negative correlations were observed between penetration resistance and moisture at the $99 \%$ level of confidence in 2016 with simple correlation coefficients of $-0.694,-0.615$ and -0.741 , for the first, second and third drops, respectively. Negative correlations were observed again in 2017, but only the second and third drops were statistically significant. Straw and Henry (2018) reported negative correlation coefficients between volumetric water content and penetration resistance. However, some measurements were not significantly different. They also found weaker correlations on the sand-capped fields compared to the native soil fields tested. This was similar to what Caple et al. (2012) found on fields with varying soil textures. 
The strongest correlations in this study were observed between penetration resistance and surface hardness. Positive correlations ranged from 0.517 to 0.777 through both years. Nevertheless, because the penetrometer allows probing into a deeper soil profile, the two methods should be complementary and used together (Li et al., 2009).

Kinetic penetration between drops also showed large positive correlations between subsequent drops in both years. This may indicate the general level of soil compaction at a given location and the soil shear strength of the soil layers are naturally correlated.

Table 11. Correlation between parameters three months after the construction of plots in 2016.

\begin{tabular}{lcccccc}
\hline & Moisture & $\mathrm{G}_{\max }$ & Traction & KR Drop1 & KR Drop2 & KR Drop3 \\
\hline Moisture & 1 & $-0.449^{\text {ns }}$ & $0.282^{\text {ns }}$ & $-0.694^{* *}$ & $-0.615^{* *}$ & $-0.741^{* *}$ \\
Gmax & & 1 & $-0.157^{\text {ns }}$ & $0.777^{* *}$ & $0.682^{* *}$ & $0.771^{* *}$ \\
Traction & & & 1 & $-0.134^{\text {ns }}$ & $-0.486^{*}$ & $-0.357^{\text {ns }}$ \\
KR Drop 1 & & & & 1 & $0.789^{* *}$ & $0.804^{* *}$ \\
KR Drop 2 & & & & & 1 & $0.747^{* *}$ \\
KR Drop 3 & & & & & & 1 \\
\hline
\end{tabular}

$\mathrm{KR}$, kinetic penetrometer resistance.

*, significant at 0.05 probability level.

**, significant at 0.01 probability level.

Table 12. Correlation between parameter three months after the construction of plots in 2017.

\begin{tabular}{lcccccc}
\hline & Moisture & $\mathrm{G}_{\max }$ & Traction & KR Drop1 & KR Drop2 & KR Drop3 \\
\hline Moisture & 1 & $-0.462^{*}$ & $-0.106^{\mathrm{ns}}$ & $-0.370^{\text {ns }}$ & $-0.835^{* *}$ & $-0.571^{*}$ \\
$\mathrm{G}_{\max }$ & & 1 & $0.406^{\mathrm{ns}}$ & $0.517^{*}$ & $0.595^{* *}$ & $0.626^{* *}$ \\
Traction & & & 1 & $0.165^{\mathrm{ns}}$ & $0.046^{\mathrm{ns}}$ & $0.213^{\text {ns }}$ \\
KR Drop 1 & & & 1 & $0.523^{*}$ & $0.505^{\star}$ \\
KR Drop 2 & & & & & 1 & $0.510^{*}$ \\
KR Drop 3 & & & & & & 1 \\
\hline
\end{tabular}

$\mathrm{KR}$, kinetic penetrometer resistance.

*, significant at 0.05 probability level.

${ }^{* *}$, significant at 0.01 probability level. 


\section{CONCLUSIONS}

The results of this two-year study showed that the rootzone moisture content, surface hardness, traction, kinetic penetration and visual turfgrass quality reached the minimum suggested levels where a standard exists. However, we did not deem any of the measurements taken to be considered too high and unsafe for natural turfgrass athletic fields. Many of these parameters have room for improvement before reaching the maximum thresholds especially for competitive sports that are highly destructive to the playing surfaces.

Surface hardness was greatest in the inorganic stabilizer and the wheat straw treatments. Penetrometer resistance was greater in the both of the more fibrous materials used, the straw and the inorganic StaLok treatments, compared to the other organic materials tested. This could be due to the fibers of the two treatments mimicking the fibrous roots and rhizomes of an established stand of Kentucky bluegrass.

We found no significant differences in traction between any of the treatments which may be attributed more to the sod surface than the rootzone treatments. Differences in volumetric water content were observed. The treatment with the highest rate of peat showed the highest moisture content measured but not always significantly different than the other organic amendments tested; the inorganic stabilizing fibers showed the lowest rootzone moisture content on all measured dates.

The inorganic stabilizer treatment was the only one to produce below acceptable quality ratings in the fourth month after construction in both years. This is most likely because it also had the lowest moisture content in each month tested.

Negative correlations were found between moisture content and surface hardness and between moisture content and penetration resistance. A concurrent research project is being conducted to test different rates of the materials used in combination with different fertility rates, and the speed of degradation of organic amendments. Additional research may focus on different mixing techniques to produce a highly homogenous blend of materials.

Wheat straw could be used as a short-term stabilizing fiber when mixed into a sand-based rootzone knowing the organic material will degrade and cause fewer long-term issues compared to the use of an inorganic stabilizing fiber that will not degrade. Using combinations of peat and wheat straw 
may be beneficial and future research could determine the proper rates of each material. Management practices were limited in this experiment, so additional athletic turf maintenance procedures, such as aerification, topdressing and increased fertility, could be included in further studies. One of the most important aspects of similar athletic field research is measuring stability after sporting events, so further research with traffic simulations would be recommended. 


\section{REFERENCES}

Adams, W.A. 1981. Soils and plant nutrition for sportsturf: perspective and prospects. Proc. of the International Turfgrass Research Conference. 4: p.167-179.

Adams, W.A., and R.J. Gibbs. 1989. The use of polypropylene fibres (VHAF) for the stabilization of natural turf on sports fields. Proc. of the Sixth Int. Turfgrass Res. Conf., Tokyo, Japan. 31 July - 5 August 1989. Int. Turfgrass Soc, and Japanese Soc. of Turfgrass Sci., Tokyo, Japan.

Adams, W.A., and R.J. Gibbs. 1994. Natural Turf for Sport and Amenity: Science and Practice. CAB International, Wallingford, Oxon, OX10 8 DE, UK.

Aldahir, P.C.F., and J.S. McElroy. 2014. A review of sports turf research techniques related to playability and safety standards. Agron. J. 106(4): 1297-1308.

American Society for Testing and Materials. 2004. Standard guide for construction of high performance sand-based rootzones for sports fields. ASTM. F2396-04.

Anderson, J.D., F. Rimi, M. D. Richardson, S. Macolino, and D.E. Karcher. 2014. Kentucky bluegrass response to establishment methods and cultural practices in a sand-based system and native soil. Agron. J. 106:351-358.

Anderson, M., and T. VanLoo. 2005. Preparing for the Athens Olympics. Proceedings of the $75^{\text {th }}$ Annual Michigan Turfgrass Conference 75:1-3.

Baker, S.W. 1991. Temporal variation of selected mechanical properties of natural turf football pitches. J. of the Sports Turf Res. Institute. 62:63-92.

Baker, S.W. 1997. The reinforcement of turfgrass areas using plastics and other synthetic materials: a review. Int. Turfgrass Soc. Res. J. 8:3-13.

Baker, S.W., and P.M. Canaway. 1993. Concepts of playing quality: criteria and measurement. Int. Turfgrass Soc. Res. J. 7:172-181.

Baker, S.W., S.J. Mooney, and A. Cook. 1999. The effects of sand type and rootzone amendments on golf green performance. I. soil properties. J. Turfgrass Sci. 75:2-17.

Beard, J.B., D.P. Martin, and F.B. Mercer. 1977. Investigation of net sod production as a new technique. Int. Turfgrass Soc. Ref. J. 3:353-360. 
Beard, J.B., and R.L. Green. 1994. The Role of Turfgrasses in Environmental Protection and Their Benefits to Humans. J. Environ. Qual. 23:452-460.

Bell, M.J., S.W. Baker, and P.M. Canaway. 1985. Playing quality of sports surfaces. A review. J. Sports Turf Res. Inst. 61:26-45.

Bradford, J.M., D.A. Farrell, and W.E. Larson. 1971. Effect of soil overburden pressure on penetration of fine metal probes. Soil Sci. Soc. Am. Proc. 35:12-15.

Bradley, B. 2014. Penn St. program tries to prevent concussions by examining surfaces. NFL. http://www.nflevolution.com/article/penn-st-program-tries-to-prevent-concussions-by-examiningsurfaces?ref=0ap2000000323619 (accessed 20 Nov. 2016).

Caple, M., I. James, and M. Bartlett. 2012. Spatial analysis of the mechanical behavior of natural turf sports pitches. Sports Engineering. 15 (3): 143-157.

Canaway, P.M. 1993. Effects of using seed, sod and juvenile sod for the establishment of an all-sand golf green turf and on its initial performance under wear. Int. Turfgrass Soc. Res. J. 7:469-475.

Canaway, P.M., and M.J Bell. 1986. Technical note: An apparatus for measuring traction and friction on natural and artificial playing surfaces. J. Sports Turf Res. Inst. 62:211-214.

Carrow, R.N., and A.M. Petrovic. 1992. Effects of traffic on turfgrasses. In: Waddington, D.V., R.N. Carrow, and R.C. Shearman, editors, Turfgrass. ASA, CSSA, and SSSA. Madison, WI. p. 285330.

Casimaty, B.G., J. Neylan, and J.B. Beard. 1993. Effects of soil removal by postharvest hydraulic washing on sod transplant rooting of a kentucky bluegrass-perennial ryegrass poly stand and a creeping bentgrass monostand. Int. Turfgrass Soc. Res. J. 7:850-856.

Clegg, B. 1976. An impact testing device for in situ base course evaluation. Aust. Road Res. Board Proc. $8(8): 1-6$

Cockerham, S.T., V.A. Gibeault, and R.A. Khan. 1993. Alteration of sports field characteristics using management. Int. Turfgrass Soc. Res. J. 7:182-191.

Cook, A., and S.W. Baker. 1998. Organic amendments for sand-dominated rootzones. In. Farrally, M.R. and A.J. Cochramn (ed.) P. 637-646. Proceedings of the 1998 world scientific congress of golf. St. Andrews, Scotland; 20-24 July, 1998. 
Davis, W.B., J.L. Paul, J.H. Madison, and L.Y. George. 1970. A guide to evaluating sands and amendments used for high trafficked turfgrass. Univ. of California Agri. Ext. AXT-n 113.

Depdew, M. W., Nelson, S. D., and Pulley, G. E. 1998. Comparison of a Clegg Impact Hammer with cone penetrometer. 1998 Annual Meeting Abstracts. 135.

Dest, W.M., K. Guillard, and S. Ebdon. 2005. The effects of reinforcement inclusions on wear tolerance, playing quality and physical properties in a silt loam and sand rootzone matrix. Int. Turfgrass Soc. Res. J. 10:1049-1059.

Dickson, K.H., J.C. Sorochan, J.T. Brosnan, J.C. Stier, J. Lee, and W.D. Strunk. 2018. Impact of soil water content on hybrid Bermudagrass athletic fields. Crop Sci. 58:1416-1425.

Dickson, K.H., J.C. Sorochan, J.T. Brosnan, J.C. Stier, J.M. Zobel, and A.W. Thomas. 2017. Crumb rubber depth is more important than particle size for improving bermudagrass traffic tolerance. Crop Sci. 57:2837-2842.

Fédération Internationale de Football Association. 2015. Handbook of test methods. FIFA Quality programme for football turf. October. https://football-technology.fifa.com/media/1238/fqphandbook-of-test-methods-v27.pdf

Follis, C.C., S.H. Anderson, E.H. Ervin, and B.S. Fresenburg. 2013. Assessment of rootzone mixes with inorganic and organic amendments for athletic fields. Int. Turfgrass Soc. Res. J. 12:633-639

Freitag, D.R. 1968. Penetration tests for soil measurements. Trans. Am. Soc. Agric. Eng. 11:750-753.

Garman, W.L. 1952. The permeability of various grades of sand and peat and mixures of these with soil and vermiculite. USGA. J. Turf Manage. 6(1): 27-28.

Gelernter, W., and L.J. Stowell. 2001. The question is compaction: is bulk density the answer? Pace Insights. January. 7(1): 1-4.

Gerrard, A.J. 1982. The use of hand-operated soil penetrometers. Area 14:227-234.

Goodall, S.A., K. Guillard, W.M. Dest, and K.R. Demars. 2005. Ball response and traction of skinned infields amended with calcined clay at varying soil moisture contents. Int. Turfgrass Soc. Res. J. 10(2):1085-1093.

Henderson, J., N. Miller, and K. Guillard, O. Harel, and B. Raman. 2009. Late fall sod installation produces equivalent or greater rooting strength of Poa pratensis than typical spring installations 
during the subsequent growing season. Applied Turfgrass Sci. Online. Doi:10.1094/ATS-20090724-01-RS.

Herrick, J.E., and T.L. Jones. 2002. A dynamic cone penetrometer for measuring soil penetration resistance. Soil Sci. Soc. Am. J. 66:1320-1324.

Hillel, D. 1998. Environmental Soil Physics. Academic Press. San Diego, CA.

Holmes, G., and M.J. Bell. 1986. A pilot study of the playing quality of football pitches. J. of the Sports Turf Res. Institute. 62:74-91.

Holmes, B., and S. Cruz. 1994. World Cup's field of dreams. New Scientist. 142:5

Hummel, N.W. 2000. What goes best with sand: peat, soil or compost? Golf Course Management. April. p.57-60.

Kanaan, A., M. Serena, E. Sevostianova, I. Sevostianov, and B. Leinauer. 2018. ASA, CSSA and SSSA International Annual Meetings. p. 112051.

Li, D. 2001. Quantitative evaluation of sand shape and roundness and their potential effect on stability of sand-based athletic fields. Ph.D. diss., lowa State University, Ames.

Li, D, D.D. Minner, and N.E. Christians. 2009. Evaluation of factors contributing to surface stability of sand-based turf. Agron. J. September/October. 101(5): 1160-1167.

Li, D., W. Fang, and L. Han. 2011. Nitrogen fertilization influences shear strength and quality of Kentucky bluegrass sod grown on clay. Agron. J. 103:751-755.

Lulli, F., C. de Bertoldi, R. Armeni, L. Guglielminetti, and M. Volterrani. 2014. Warm-season Turfgrass Species Generate Sports Surfaces with Different Playability. HortTechnology. December. 24(6): 749-756.

Mack, C.D., E.B. Hershman, R.B. Anderson, M.J. Coughlin, A.S. McNitt, R.R. Sendor, and R.W. Kent. 2019. Higher Rates of Lower Extremity Injury on Synthetic Turf Compared With Natural Turf Among National Football League Athletes. The Am. J. of Sports Medicine. 47(1):189-196.

McClements, I., and S.W. Baker. 1994. The Playing quality of rugby pitches. J. of the Sports Turf Res. Institute. 70:29-43.

McNitt, A.S., and P.J. Landschoot. 2005. The effects of soil reinforcing materials on the traction and divot resistance of a sand root zone. Int. Turfgrass Soc. Res. J. 10: 1115-1123 
NFL Players Association. 2010. 2010 NFL Players Playing Surfaces Opinion Survey. Washington, D.C. NFL Players Association. 25 pp.

Orchard, J. 2001. The AFL penetrometer study: Work in progress. J. of Sci. and Medicine in Sport. 4(2): 220-232.

O'Sullivan, M.F., J.W. Dickson, and D.J. Campbell. 1987. Interpretation and presentation of cone resistance data in tillage and traffic studies. J. Soil Sci. 38:137-148.

Puhalla, J.C., J.V. Krans, and J.M. Goatley, Jr. 2010. Sports Fields, design, construction, and maintenance. $2^{\text {nd }}$ Ed. John Wiley \& Sons, Inc.

Richards, C.W. 1994. The effects of mesh element inclusion on soil physical properties of turfgrass rootzones. J. Sports Turf Res. Inst. 70:110-118.

Rieke, P.E., and J.B. Beard. 1969. Factors in sod production of Kentucky bluegrass. Proc. First. Int. Turfgrass Res. Conf. 1:514-521.

Rogers, J.N. III. 1988. Impact Absorption and Traction Characteristics of Turf and Soil Surfaces. Ph.D. Dissertation: Pennsylvania State University. xiv, 144, [1]

Rogers, J.N., and D.V. Waddington. 1992. Impact absorption characteristics on turf and soil surfaces. Agron. J. 84:203-209.

Serensits, T. J., A.S. McNitt, and D.M. Petrunak. 2011. Human health issues on synthetic turf in the USA. Proceedings of the Institution of Mechanical Engineers:Part $\mathrm{P}$, Journal of Sports Engineering and Technology. September. 225(3): 139-146.

Shearman, R.C., T.R. Turner, K.N. Morris, R.E. Gaussoin, M.R. Vaitkus, and L.A. Wit. 2001. Sod strength and lateral spread pf Poa pratensis cultivars and experimental lines. Int. Turfgrass Soc. Res. J. 9:928-933.

Shepard, D.P. 1978. Comparison of physical and chemical properties of commercial and indigenous forms of organic matter in golf green soil mixtures. M.S. thesis. The Univ. of Tennessee, Knoxville.

Shim, G.Y., C.S. Kim, S.H. Lee, and Y.K. Joo. 2004. Effects of sodding and seeding time and rate of seed mixture on the establishment of cool-season turfgrasses. Kor. Turfgrass Sci. 18:179-191. 
Stier, J.C., J.N. Rogers III, J.R. Crum, and P.E. Rieke. 1999. Flurprimidol effects on Kentucky bluegrass under reduced irradiance. Crop Sci. September/October. 39(5): 1423-1430.

Straw, C.M., and G.M. Henry. 2018. Spatiotemporal variation of site-specific management units on natural turfgrass sports fields during dry down. Precision Agriculture. June. 19 (3): 395-420.

Tencza, R., J. Henderson, and K. Guillard. 2015. Protecting quality and integrity of turfgrass surfaces during non-sporting events with portable roadways. Crop, Forage and Turfgrass Management. $1: 1-11$

Turfgrass Resource Center. Facts about artificial turf and natural grass. Turfgrass Producers International. East Dundee, IL. www.turfgrasssod.org/trc/index/html

Turgeon, A.J. 1999. Beaver stadium: A decision case in football field management. J. Nat. Resour. Life Sci. Educ. 28:74-78.

USGA Green Section Staff. 1993. USGA recommendations for a method of putting green construction. USGA Green Sect. Rec. 31(2):1-3.

USGA Green Section Staff. 2004. USGA recommendations for a method of putting green construction. Available at: http://www.usga.org/course_care/articles/construction/greens/Green-SectionRecommendations-For-A-Method-Of-Putting-Green-Construction/

Van Wijk, A.L.M. 1980. A Soil Technological Study on Effectuating and Maintaining Adequate Playing Conditions of Grass Sports Fields. Wagebingen: Centre for Agricultural Publishing and Documentation. 124.

Vaz, C.M.P., and J.W. Hopmans. 2001. Simultaneous measurement of soil penetration resistance and water content with a combined penetrometer-TDR moisture probe. Soil Sci. Soc. Am. J. 65:4-12.

Walker, K.S., and E.G. Walker II. 2018. Pre-game agronomic field safety assessment for sports fields: Future implications for risk assessment. ASA, CSSA and SSSA International Annual Meetings. 112475.

Williams, S. 2002. More modules: Reliant stadium's turf manager leaves Magic Kingdom for NFL. SportsTurf. 18(10):14-16. 